\title{
Evaluation of Ecological Environmental Pollution in Green Building Construction
}

\section{Shang Li}

Institute of Architecture Engineering, Huanghuai University, Zhumadian 463000, China

Corresponding author: Shang Li; $115455561 @$ qq.com

\section{Nat. Env. \& Poll. Tech.} Website: www.neptjournal.com

Received: 15-05-2021

Revised: 30-06-2021

Accepted: 02-07-2021

Key Words:

Green building

Construction process

Ecological environment

Pollution evaluation

\begin{abstract}
The long-term extensive development mode of China's construction industry has resulted in the enormous consumption of energy resources, increasingly severe environmental pollution, and serious ecosystem degradation. Green construction is an essential route to implement the ecological civilization construction policy and achieve green building in China's construction industry. However, enormous environmental pollution has been generated because of a series of problems in China's green building construction, such as the lack of a scientific evaluation system for green building construction, loose field construction management, and weak awareness of environmental protection among constructors. Therefore, in this study, a pollution evaluation index system for green building construction was established from three aspects, namely, resource utilization, environmental load, and environmental management, to evaluate the class of ecological environmental pollution triggered by green building construction. Next, a model combining the analytic hierarchy process (AHP) and fuzzy comprehensive evaluation was built, followed by a case study. The results revealed that resource utilization was the main factor causing ecological environmental pollution in green building construction, accounting for $63.70 \%$. Energy conservation and application of new pollution control technology were level III factors that should be given considerable attention. In the fuzzy comprehensive evaluation, the degree of membership of "good" was 0.4855 , which was the maximum, indicating that the ecological environment of green building construction in this study was at "good" level, thereby indicating the environmental friendliness of green building construction. This study will be of positive reference values for identifying the ecological influencing factors of green building construction, reducing the waste of resources of green buildings, promoting green construction technologies, and innovating green construction management.
\end{abstract}

\section{INTRODUCTION}

With the development and promotion of industrialization, urbanization, and intelligence, industrial production is accompanied by a serious waste of resources and energy and environmental pollution, and building construction has generated the most direct and evident environmental impacts. As an important constituent part of the national economy, the construction industry is a significant industry boosting China's urbanization, but it is also a major cause of the environmental crisis. The construction industry, an important pillar of the national economy, has always been under the rapid development state in recent years. Despite being a pillar industry of the national economy, the construction industry is also characterized by enormous resource consumption and severe environmental pollution. As shown in Fig. 1, the total energy consumption of China's construction industry rapidly increased from 22,550,200 tons of standard coal in 2001 to $86,850,000$ tons of standard coal in 2018 , with an annual average growth rate of $16.77 \%$. The resource and energy consumption and environmental pollution degree caused by building construction are serious because most construction units are still performing extensive construction operation, lacking the cognition and application of the theory of green building construction.

Green building construction refers to integrating environmental and resource protection into the construction, during which the conservation of energy, land, water resources, and building materials and environmental protection are achieved through scientific planning and management, and the resources are utilized to the greatest extent to reduce the waste of resources and mitigate the environmental pollution. The emergence of green building construction can not only improve the environmental protection problems and exert an evident effect on the social resource consumption in the construction industry but also relieve the pollution brought by the discharge of construction wastes during building construction, thereby reducing the pollution of the whole construction industry and promoting environmental protection. However, the layout of the construction site is disorderly; dust and noise pollution is serious, and the related standards of green building construction have not been completely met 
in China's construction industry. Therefore, improving the reasonable ecological environmental pollution evaluation index system and evaluation and measurement methods for green building construction will be of guiding significance for construction units to practice green construction, save resources, protect the environment, and promote the sustainable development of the building construction industry.

\section{EARLIER STUDIES}

Green construction can achieve the enterprise goals with high efficiency, high standard, and high quality in construction projects, which can not only promote the development of a low-carbon economy but also maximize the socio-economic benefits. Hence, it has been widely applied in developed European and American countries. As for the evaluation of environmental benefits resulting from green building construction, Zhai et al. comparatively analyzed the heating, air conditioning, natural ventilation, and hot water supply systems of green buildings and traditional buildings in Shanghai. The results show that the integrated solar energy system of green buildings has high utilization efficiency, and it can reduce building energy consumption by approximately $30 \%$ (Zhai et al. 2008). Kim et al. evaluated and analyzed the green construction level in the construction phase from five angles, namely, energy consumption, material saving, utilization of water resources, environmental impact, and land utilization, analyzed the causes of the environmental pollution generated in each working procedure, and proposed the countermeasures and suggestions (Kim et al. 2011). Ghaffarian Hoseini et al. expounded the contemporary trend and application of green building and the influence of green building design on sustainable development. The results show that the sustainable energy source performance of green building has been transformed into a wise and feasible solution, thereby reducing carbon dioxide emissions and energy consumption of construction sectors (Ghaffarian Hoseini et al. 2013). Asdrubali et al. reported that the overall performance evaluation of green building was a complicated problem involving various aspects of building construction, energy sources, and environment and extended the monitoring of buildings in the Umbria area, Italy, and the results show that green building can reduce the environmental pollution caused by building energy consumption (Asdrubali et al. 2013). Sinha et al. stated the relationship between green building and sustainable development and discussed how the use of green building materials could mitigate the environmental pollution caused by building construction (Sinha et al. 2013). Chaudhary et al. analyzed the energy rating system of green buildings and explored the specific energy consumption and total energy consumption of typical buildings, and the results reveal that green construction can improve environmental pollution in comparison with the traditional concrete pouring-type buildings (Chaudhary et al. 2013). Parrish et al. constructed a green building evaluation index system based on a full life cycle and proposed the countermeasures in increasing the green construction level in each construction procedure (Parrish et al. 2014). Based on the evaluation factors of the green building evaluation system, Nilashi et al. combined the analytic hierarchy process (AHP) with the fuzzy logic method to evaluate the environmental performance of the green building, and the results show that this method system is a performance evaluation tool that is used to analyze the effects of various factors on the sustainable development of building construction (Nilashi et al. 2015). Al-Ghamdi et al. explored the application of the green building rating system from a system level, and the results indicated that the use of renewable energy systems resulted in an enormous economic burden on the field, but it can effectively improve the environmental benefits (Al-Ghamdi et al. 2016). Qin et al. evaluated the environmental risk factors of green buildings, and the study results showed the difference in risk importance among stakeholders, thereby providing a basis for different project participators to implement the corresponding risk management strategies according to their understanding of risk importance (Qin et al. 2016). Vidushini, S. et al. thought that the Singaporean construction industry consumed half of the energy sources in China and evaluated the four constituent parts of the Singapore Department Innovation System: technical system, market demand, doer interaction, and application of network and system framework. In addition, the results show that the further development of the Singaporean green building industry is hindered by the unwillingness of building users to change their habits, ineffective coordination among stakeholders, and mere innovation support of green buildings from the government (Vidushini et al. 2017). Hsieh et al. stated that more extensive green building construction could be promoted if the government sent stronger signal intensity to the green building industry (Hsieh et al. 2017). Wang et al. promoted a dynamic method to quantify the difference between expected and actual energy use in green building construction. The case study results show that the dynamic performance gaps among five buildings range from $3.0 \%$ to $53.5 \%$, and the control performance degradation of the HVAC system may be the primary cause of the performance gap (Wang et al. 2020). Fu et al. analyzed the complicated relationship among the green behaviors of stakeholders and explored the driving paths of the green building industry based on the network analysis. The study results indicate that the development of the green building industry is important for implementing the green strategy and achieving the transformation and upgrading of the con- 
struction industry (Fu et al. 2020). Razmjoo et al. believed that green building construction was of great significance for the development of the smart city; therefore, the government should achieve the coordinated development of society and the environment by implementing new green building energy policies (Razmjoo et al. 2021). Existing literature shows that although the concept of green building construction has been proposed differently in the globe and each country has its unique orientation, it is highly correlated with sustainable building, sustainable construction, green building, environment-friendly construction, and clean production, indicating that green construction is the technical embodiment of sustainable development of construction enterprises in the engineering construction link. In developed countries, particular attention is paid to "green building materials," where considerable research progress has been achieved to save material and energy sources, reduce the waste of materials during construction, mitigate the pollution of the construction site, lower the construction cost, and lengthen the service life of buildings. However, many challenges have been identified in the current green construction management in China, and the related policies and managerial supervision lack comprehensiveness and operability. Therefore, in this study, the AHP was combined with a fuzzy comprehensive evaluation to evaluate the class of environmental pollution caused by the construction of one green building and provide research ideas for future studies.

\section{MODEL PROFILE AND INDEX SYSTEM}

\section{AHP-Fuzzy Comprehensive Evaluation Method}

The AHP-fuzzy comprehensive evaluation method must determine the domain for the factors of the evaluation object, namely, $M$ evaluation indexes.

$$
u=\left\{u_{1}, u_{2}, \cdots \cdots, u_{m}\right\}
$$

Next, the domain for the evaluation grade is determined using formula (2).

$$
v=\left\{v_{1}, v_{2}, \cdots \cdots, v_{m}\right\}
$$

Subsequently, the evaluation objects are quantified one

by one from each factor $u_{i}(i=1,2, \cdots \cdots, n)$ to obtain the following fuzzy relation matrices:

$$
R=\left[\begin{array}{cc}
R \mid & u_{1} \\
R \mid & u_{2} \\
\cdots \\
R \mid & u_{n}
\end{array}\right]=\left[\begin{array}{cccc}
r_{11} & r_{12} & \cdots & r_{1 m} \\
r_{21} & r_{22} & \cdots & r_{2 m} \\
\cdots & \cdots & \cdots & \cdots \\
r_{n 1} & r_{n 2} & \cdots & r_{n m}
\end{array}\right]
$$

In matrix $R$, the factor in row $i$ column $j$ represents the membership of one evaluation object to the fuzzy subset of grade $v_{j}$ from the factor $u_{i}$. The performance of an evaluation object from the aspect of one factor $u_{i}$ is depicted through the fuzzy vector $\left(R \mid u_{i}\right)=\left(r_{i 1}, r_{i 2}, \cdots \cdots, r_{i m}\right)$, but it is mostly depicted by other evaluation methods using the actual value of one index. Thus, the weight vector of evaluation factors is determined. In the fuzzy comprehensive evaluation, the weight vector of evaluation factors is determined using formula (4):

$$
Q=\left(q_{1}, q_{2}, \cdots \cdots, q_{m}\right)
$$

In formula (4), the factor $q_{i}$ in the weight vector $Q$ is the membership of factor $u_{i}$ to the fuzzy subset. In this study, the AHP was used to determine the relative importance of

Table 1: Evaluation index system of pollution induced by green building construction.

\begin{tabular}{lll}
\hline Level I index & Variable No. & Level II index \\
\hline Resource utilization & V1 & Construction waste recycling \\
& V2 & Energy conservation \\
V3 & Use conditions of new energy resources \\
V4 & Application of new pollution control technology \\
Environmental load & V5 & Atmospheric pollution \\
& V6 & Noise pollution \\
& V8 & Water pollution \\
V9 & Light pollution \\
V10 & Solid waste pollution \\
V11 & Soil pollution \\
& V12 & Qualification of green construction \\
& V13 & Safety of green construction \\
& V14 & Supervision of green construction \\
\end{tabular}


evaluation indexes, namely, $\sum_{i=1}^{n} q_{i}=1, q_{i} \geq 0$, and $i=1,2, \cdots$, $n$. Next, $Q$ was synthesized using $R$ of each evaluation object to obtain fuzzy comprehensive evaluation results (vector $B$ ) of each evaluation object:

$$
B=Q \times R=\left(q_{1}, q_{2}, \cdots \cdots, q_{n}\right)\left[\begin{array}{cccc}
r_{11} & r_{12} & \cdots & r_{1 m} \\
r_{21} & r_{22} & \cdots & r_{2 m} \\
\cdots & \cdots & \cdots & \cdots \\
r_{n 1} & r_{n 2} & \cdots & r_{n m}
\end{array}\right]
$$

\section{Index System}

Building construction is a complicated system with relatively complicated evaluation algorithms. The overall objectives of green building evaluation were generalized and classified to construct a scientific and reasonable green building evaluation index system. The green building construction index system was established and perfected on the basis of the concept of sustainable development, which specifically included environmental load, resource-saving, integrated management, and construction effect. Furthermore, the hierarchical evaluation model of this green building construction index system was optimized (Table 1).

\section{THE CASE STUDY}

Some of the green construction evaluation indexes that could be directly expressed by quantitative data could be accessed through questionnaire surveys, expert consultation, etc. Some quantitative indexes could be identified using specific values, such as power consumption, the recovery rate of construction water, waste discharge, and loss rate of building materials, which were primarily determined on the basis of the numerical values widely accepted by related national standards, specifications, and technical standards. The evaluation criteria for qualitative analysis of indexes could be formulated by discussion among experts and engineers. The evaluation index system was established by combining the evaluation theory of green buildings and green projects. In addition, the environmental protection and energy conservation indexes were screened out, and the AHP was used to measure the weights of 14 level II indexes (Table 2).

In this study, the evaluation result was divided into the following grades (excellent, good, ordinary, relatively poor, and poor). The statistical evaluation results were obtained through the questionnaire survey method. The number of experts was denoted as $\mathrm{M}$. For example if $\mathrm{N}$ experts gave the evaluation grade Vi to this index, then the membership of this index to Vi could be calculated using the formula N/M. Similarly, the above-mentioned steps were repeated to obtain the membership matrix of this qualitative index. The membership of each index was obtained by calculating the frequency at different grades. The management of prefabricated green building construction in an economic development zone in Shandong Province, China, was implemented in this study. A total of 12 experts within the construction industry, six proprietor representatives, eight project managers, and 24 constructors were invited, and 50 questionnaires were given. The questionnaire survey results were organized and calculated, and the results are shown in Table 3.

According to formulas (1)-(5), the fuzzy evaluation matrix of level I indexes can be calculated as follows:

$$
\left[\begin{array}{lllll}
0.1384 & 0.5883 & 0.1531 & 0.0721 & 0.0481 \\
0.1853 & 0.4238 & 0.2949 & 0.0960 & 0.0000 \\
0.2085 & 0.2569 & 0.1768 & 0.1957 & 0.1621
\end{array}\right]
$$

Table 2: Weights of environmental pollution factors during green building construction.

\begin{tabular}{lll}
\hline Weight of level I index & Weight of level II index & Total weight \\
\hline \multirow{2}{*}{0.6370} & 0.1141 & 0.0727 \\
& 0.4809 & 0.3063 \\
& 0.0691 & 0.0440 \\
& 0.3359 & 0.2140 \\
0.1047 & 0.1817 & 0.0190 \\
& 0.1680 & 0.0176 \\
& 0.1984 & 0.0208 \\
0.2583 & 0.0489 & 0.0051 \\
& 0.1534 & 0.0161 \\
& 0.2496 & 0.0261 \\
& 0.1330 & 0.0343 \\
& 0.4931 & 0.1274 \\
\hline
\end{tabular}


Next, the fuzzy comprehensive evaluation vector was calculated as $\left[\begin{array}{lllll}0.1614 & 0.4855 & 01741 & 0.1065 & 0.0725\end{array}\right]$. The fuzzy comprehensive evaluation vector showed that the membership of "good" was 0.4855 , which was the maximum. In this case study, the environmental pollution caused by green building construction was at "good" grade, being better than the ordinary traditional concrete pouring-type building construction, which verified the scientificity of green building construction. Green building construction can mitigate environmental pollution triggered by traditional construction primarily because personnel training was performed well in green construction, and constructors were regularly organized to accept the training regarding green and environmental protection. This project showed great performance in saving water, utilizing water resources, saving land, and protecting land resources. Water was saved, and the water use management system was formulated in strict accordance with the related standard. The standard requirements can be basically satisfied with regard to safety and civilized construction management, the health status of constructors, construction organization plan, occupational health, and safety training.

\section{POLICY SUGGESTIONS}

\section{Constructing A Perfect Green Construction Organization Management System}

Strengthening the cognition of green building management among employees and reinforcing the management of job responsibilities of managerial staff were necessary. Green building organization management focused on establishing a green construction management system. Managerial staff should implement a clear division of labor and arrange green construction managers and supervisors to ensure and promote the implementation of green projects. Transverse and longitudinal green construction and management organizations should be established, and the green construction responsibilities of each level and each department should be clearly defined. Moreover, job responsibilities should be carefully implemented; the list of job contents should be clarified, and the respective responsibilities should be fulfilled to boost green project construction. A systematic management system should be established to achieve systematic management from the aspects of personnel management, unit management, personal and unit information management, and job $\log$ management according to the features of construction enterprises and project construction.

\section{Strengthening the Propaganda and Implementing Green Construction}

Green construction can not only save energy resources and costs and reduce consumption but also effectively improve the core competitiveness of enterprises and elevate their management and technical levels. Strengthening green construction among employees is important to improve green construction management and implementation levels. Therefore, a regular training class should be set up. The material incentive method may be adopted to encourage employees to

Table 3: Membership of statistical survey results.

\begin{tabular}{|c|c|c|c|c|c|}
\hline Level II index & Excellent & Good & Ordinary & Relatively poor & Poor \\
\hline Construction waste recycling & 0.2000 & 0.8000 & 0.0000 & 0.0000 & 0.0000 \\
\hline Energy conservation & 0.0000 & 0.6000 & 0.1500 & 0.1500 & 0.1000 \\
\hline Use condition of new energy resources & 0.7000 & 0.1000 & 0.2000 & 0.0000 & 0.0000 \\
\hline Application of new pollution control technology & 0.2000 & 0.6000 & 0.2000 & 0.0000 & 0.0000 \\
\hline Atmospheric pollution & 0.3000 & 0.5000 & 0.2000 & 0.0000 & 0.0000 \\
\hline Noise pollution & 0.6000 & 0.1000 & 0.1000 & 0.2000 & 0.0000 \\
\hline Water pollution & 0.0000 & 0.6000 & 0.4000 & 0.0000 & 0.0000 \\
\hline Light pollution & 0.3000 & 0.5000 & 0.2000 & 0.0000 & 0.0000 \\
\hline Solid waste pollution & 0.1000 & 0.8000 & 0.1000 & 0.0000 & 0.0000 \\
\hline Soil pollution & 0.0000 & 0.2000 & 0.5500 & 0.2500 & 0.0000 \\
\hline Qualification of green construction & 0.0000 & 0.4000 & 0.2000 & 0.4000 & 0.0000 \\
\hline Safety of green construction & 0.3000 & 0.2000 & 0.2000 & 0.0000 & 0.3000 \\
\hline Supervision of green construction & 0.0000 & 0.2000 & 0.3000 & 0.3000 & 0.2000 \\
\hline Green construction system & 0.2000 & 0.3000 & 0.1000 & 0.4000 & 0.0000 \\
\hline
\end{tabular}


deepen their understanding of green buildings, or outstanding employees can be dispatched to study green buildings, thereby improving their overall quality.

\section{Enhancing the Technological Innovation of Green Construction}

The development of different kinds of technologies is the foundation of green construction. The technologies related to green construction should be developing. Recycling of construction wastes after classification is an optimization scheme for material-saving measures. Water-saving measures should be formulated to recycle groundwater and rainwater according to the practical situation. The energy conservation plan and measures should be formulated. The land-saving measures for the temporarily planned land use should also be formulated. Furthermore, related environmental protection measures should be formulated. The application of new technologies could improve the technical level of green construction, for example, BIM technology, automatic computation technology of engineering quantities, and coding technology. The corresponding measures should be formulated to reinforce the supervision of each link and implement the full life cycle management, including project approval design, contractor selection, project progress, staged acceptance check, and overall acceptance check.

\section{Constructing A Green Construction Evaluation System}

The management team of the project department must apply the comprehensive quality management method to the respective goals to facilitate the work, refine and decompose the project green construction goals, and perform dynamic management, and work should be tracked and seamlessly managed. Moreover, the independent management of employees should be implemented through goal evaluation to improve their enthusiasm and initiative. Green construction projects should be evaluated on the basis of the following five aspects: environmental protection, water conservation and utilization of water resources, material saving and utilization of material resources, energy conservation and utilization, and conservation and protection of land resources.

\section{CONCLUSIONS}

The extensive development mode of China's construction industry led to enormous consumption of energy resources and increasingly severe environmental pollution. In this study, the evaluation theory of green buildings and green projects was combined to establish an evaluation index system, and an evaluation model was established using the AHP-fuzzy comprehensive evaluation method to measure the ecological environmental level of green buildings. The results showed that resource utilization was the primary factor for the ecological environmental pollution generated during green building construction, accounting for $63.70 \%$. The fuzzy comprehensive evaluation results showed that the ecological environment of green building construction given in this case study was at "good" grade, which indicated the environmental friendliness of green building construction. Therefore, in-depth studies should be conducted from the aspects of ecological environmental monitoring of full life cycle through green building construction technology, innovation of green construction management methods, and comprehensive promotion of green construction management.

\section{REFERENCES}

Al-Ghamdi, S. G. and Bilec, M. M. 2016. On-site renewable energy and green buildings: a system-level analysis. Environmental Science \& Technology, 50(9): 4606-4614.

Asdrubali, F., Uratti, C.B., Cotana, F., Baldinelli, G., Goretti, M., Moretti, E., Aldassarri, C.B., Belloni, E., Bianchi, F. and Rotili, A. 2013. Evaluation of green buildings' overall performance through in situ monitoring and simulations. Energies, 6(12): 6525-6547.

Chaudhary, T. and Piracha, A. 2013. Effective contribution of structural engineers to green buildings and sustainability. Canadian Journal of Civil Engineering, 40(1): 97-100.

Fu, Y., Dong, N., Ge, Q., Xiong, F. and Gong, C. 2020. Driving-paths of green buildings industry (GBI) from stakeholders' green behavior based on the network analysis. Journal of Cleaner Production, 273(18): 122883.

Ghaffarian Hoseini, A., Dahlan, N. D., Berardi, U., Ghaffarian Hoseini, A., Makaremi, N. and Ghaffarian Hoseini, M. 2013. Sustainable energy performances of green buildings: A review of current theories, implementations and challenges. Renewable and Sustainable Energy Reviews, 25: 1-17.

Hsieh, L. C. and Noonan, D. 2017. Strategic behavior in certifying green buildings: an inquiry of the non-building performance value. Environmental Management, 60(2): 231-242.

Kim, Y. D., Cha, H. S., Kim, K. R. and Shin, D. W. 2011. Evaluation method of green construction technologies using integrated lcc and lca analysis. Korean Journal of Construction Engineering and Management, 12(3).

Nilashi, M., Zakaria, R., Ibrahim, O., Majid, Abd., Zaimi.M., Zin, R.M., Chugtai, M.W., Abidin, N.I.Z., Sahamir, S.R. and Yakubu, D.A. 2015. A knowledge-based expert system for assessing the performance level of green buildings. Knowledge-Based Systems, 86(sep), 194-209.

Parrish, K. and Chester, M. 2014. Life-cycle assessment for construction of sustainable infrastructure. Practice Periodical on Structural Design and Construction, 19(1): 89-94.

Qin, X., Mo, Y. and Jing, L. 2016. Risk perceptions of the life-cycle of green buildings in china. Journal of Cleaner Production, 126(jul.10): 148-158.

Razmjoo, A., Nezhad, M. M., Kaigutha, L. G., Marzband, M., Mirjalili, S., Pazhoohesh, M., Memon, S., Ehyaei, M.A. and Piras, G. 2021. Investigating Smart City Development Based on Green Buildings, Electrical 
Vehicles and Feasible Indicators. Sustainability, 13(14): 7808.

Sinha, A., Gupta, R. and Kutnar, A. 2013. Sustainable development and green buildings. Drvna Industrija, 64(1): 45-53.

Vidushini, S., Thomas, H. and Mansi, J. 2017. Green buildings in singapore; analyzing a frontrunner's sectoral innovation system. Sustainability, 9(6): 919.
Wang, D., Pang, X., Wang, W., Qi, Z. and Yin, R. 2020. Evaluation of the dynamic energy performance gap of green buildings: case studies in china. Building Simulation, 13(2).

Zhai, X. Q., Wang, R. Z., Dai, Y. J., Wu, J. Y. and Ma, Q. 2008. Experience on integration of solar thermal technologies with green buildings. Renewable Energy, 33(8): 1904-1910. 